Pramāna -J. Phys., Vol. 28, No. 5, May 1987, pp. 471-482. (C) Printed in India

\title{
Low temperature elastic behaviour of As-Sb-Se and Ge-Sb-Se glasses
}

\author{
E S R GOPAL, T S MUKUNDAN*, J PHILIP' and S SATHISH \\ Department of Physics, Indian Institute of Science, Bangalore 560012 , India \\ *Department of Physics, National College, Jayanagar, Bangalore 560011, India \\ tDepartment of Physics, University of Cochin, Cochin 682022, India
}

\begin{abstract}
The ternary glasses of arsenic and germanium with antimony and selenium can be prepared in large sizes for optical purposes. The elastic behaviour of eight compositions of each glass has been studied down to $4.2 \mathrm{~K}$ using a $10 \mathrm{MHz}$ ultrasonic pulse echo interferometer. The glasses have a normal elastic behaviour, with the velocities gradually increasing as the temperature is lowered. An anharmonic solid model of Lakkad satisfactorily explains the temperature variations. The elastic moduli of $\mathrm{Ge}_{x} \mathrm{Sb}_{10} \mathrm{Se}_{90-x}$ glasses increase linearly as the $\mathrm{Ge}$ content is increased up to $25 \mathrm{at} . \%$ and beyond this the increase is nonlinear. $(\mathrm{AsSb})_{40} \mathrm{Se}_{60}$ glasses show a linear increase in elastic moduli with increasing Sb content. The elastic moduli of $\mathrm{As}_{x} \mathrm{Sb}_{15} \mathrm{Se}_{85-x}$ glasses exhibit a drastic change near the stoichiometric composition $\mathrm{As}_{25} \mathrm{Sb}_{15} \mathrm{Se}_{60}$. These behaviours have been qualitatively explained on the basis of the structural changes in glasses.
\end{abstract}

Keywords. Elastic behaviour; As-Sb-Se glasses; Ge-Sb-Se glasses; low temperature elasticity.

PACS Nos $61 \cdot 40 ; 62 \cdot 20$

\section{Introduction}

Chalcogenide glasses have special electrical and optical properties (Baidkov 1966; Myuller 1966; Savage and Nielsen 1964; Webber and Savage 1976) and are becoming technologically important materials. These glasses can be prepared in large sizes. Their mechanical properties are quite important from the application point of view. In this paper we present the measurement of longitudinal and transverse ultrasonic velocities and elastic constants of two different classes of $\mathrm{Ge}-\mathrm{Sb}$-Se and As-Sb-Se glasses as a function of temperature from $300 \mathrm{~K}$ down to $4.2 \mathrm{~K}$. In $\S 2$ we describe the experimental methods for preparing the samples, the bonding technique and the ultrasonic velocity measurements. Section 3 discusses the results of low temperature elastic constants. These have been fitted to the Lakkad's anharmonic oscillator model. The composition dependence of the low and room temperature elastic constants has been explained using the chemically-ordered network model.

\section{Experimental methods}

\section{Sample preparation}

Samples for ultrasonic measurements should be fairly large in size, homogeneous and free of voids and perforations. Only a few glasses can be prepared with these properties 
and chalcogenides are one among them. The Ge-Sb-Se and As-Sb-Se glasses in the form of cylinders (diameter $12 \mathrm{~mm}$, thickness $4-8 \mathrm{~mm}$ ) were prepared by the melt-quenching technique. As, Sb, Se and Ge ( $99.99 \%$ pure) obtained from Kochlight Company, UK were used. The required amount of materials were placed in a cleaned quartz tube. This is evacuated to a vacuum better than $10^{-3} \mathrm{~mm}$ of $\mathrm{Hg}$ and sealed in an argon atmosphere. The sealed ampoule is placed in a horizontal rotating furnace, the temperature raised to $1000^{\circ} \mathrm{C}$ and held at this temperature for $24 \mathrm{hr}$. The rotation ensures proper mixing of the constituents. The melt is then cooled to $800^{\circ} \mathrm{C}$ and quenched in water at $90^{\circ} \mathrm{C}$. Care is taken to see that the ampoule remains vertical during quenching. The ampoule is annealed at a temperature about $5^{\circ}$ lower than the glass transition $\left(T_{g}\right)$ of the glass for an hour and then cooled slowly to room temperature. The quartz tube is broken carefully to remove the glasses without damaging the sample. Preannealing helped in removing the mechanical stress and in obtaining fairly strong samples.

For ultrasonic velocity measurements the two faces of the glasses were polished by handlapping and made parallel to each other (wedge angle better than $0.2 \mathrm{sec}$ ). The fiatness and parallelism were checked by a dial gauge and the length of the samples was measured with a micrometer at room temperature.

\section{Velocity measurements}

The longitudinal and shear wave velocities have been measured in these glasses using a pulse echo interferometer which operates at a frequency of $10 \mathrm{MHz}$ (Srinivasan et al 1975; Kartha et al 1980), and based on the McSkimin pulse superposition technique (McSkimin 1961; Papadakis 1976). Coaxial gold-plated X cut and Y cut quartz transducers (supplied by Bharat Electronics Ltd., Bangalore) of diameter $8 \mathrm{~mm}$ are used for generating longitudinal and shear waves. An adhesive from the special cellouse tape (Technical Trade Corporation, USA) has been used as a bonding material.

The bond for the ultrasonic measurements was made as follows. A thin plastic sheet with a circular aperture of about $10 \mathrm{~mm}$ diameter is cleaned and the cellouse tape is applied. This is placed on the cleaned surface of the sample and gently pressed uniformly so that the adhesive on the tape sticks to the sample. A drop of water is poured on the tape. After a few minutes the backing of the cellouse tape along with the plastic sheet is carefully peeled off with a sharp razor, leaving behind a thin layer of adhesive on the sample. The transducer is placed on this adhesive and gently pressed uniformly. This bond transfers both the longitudinal and transverse waves quite well and a good echo pattern could be obtained throughout the temperature range of $300 \mathrm{~K}$ to $4 \cdot 2 \mathrm{~K}$.

The ultrasonic velocities at low temperatures have been measured using the cryostat described elsewhere (Padaki et al 1985). Measurements were taken while the sample was cooled continuously at a slow rate of $10^{\circ} \mathrm{C}$ per hour.

\section{Results and discussions}

\subsection{Low temperature elastic constants of $\mathrm{Ge}-\mathrm{Sb}$-Se and As-Sb-Se glasses}

The ultrasonic longitudinal and transverse velocities have been measured for eight $\mathrm{Ge}-\mathrm{Sb}-\mathrm{Se}$ glasses $\left(\mathrm{Ge}_{15} \mathrm{Sb}_{10} \mathrm{Se}_{75}, \mathrm{Ge}_{20} \mathrm{Sb}_{10} \mathrm{Se}_{70}, \mathrm{Ge}_{25} \mathrm{Sb}_{10} \mathrm{Se}_{65}, \mathrm{Ge}_{30} \mathrm{Sb}_{10} \mathrm{Se}_{60}\right.$, 

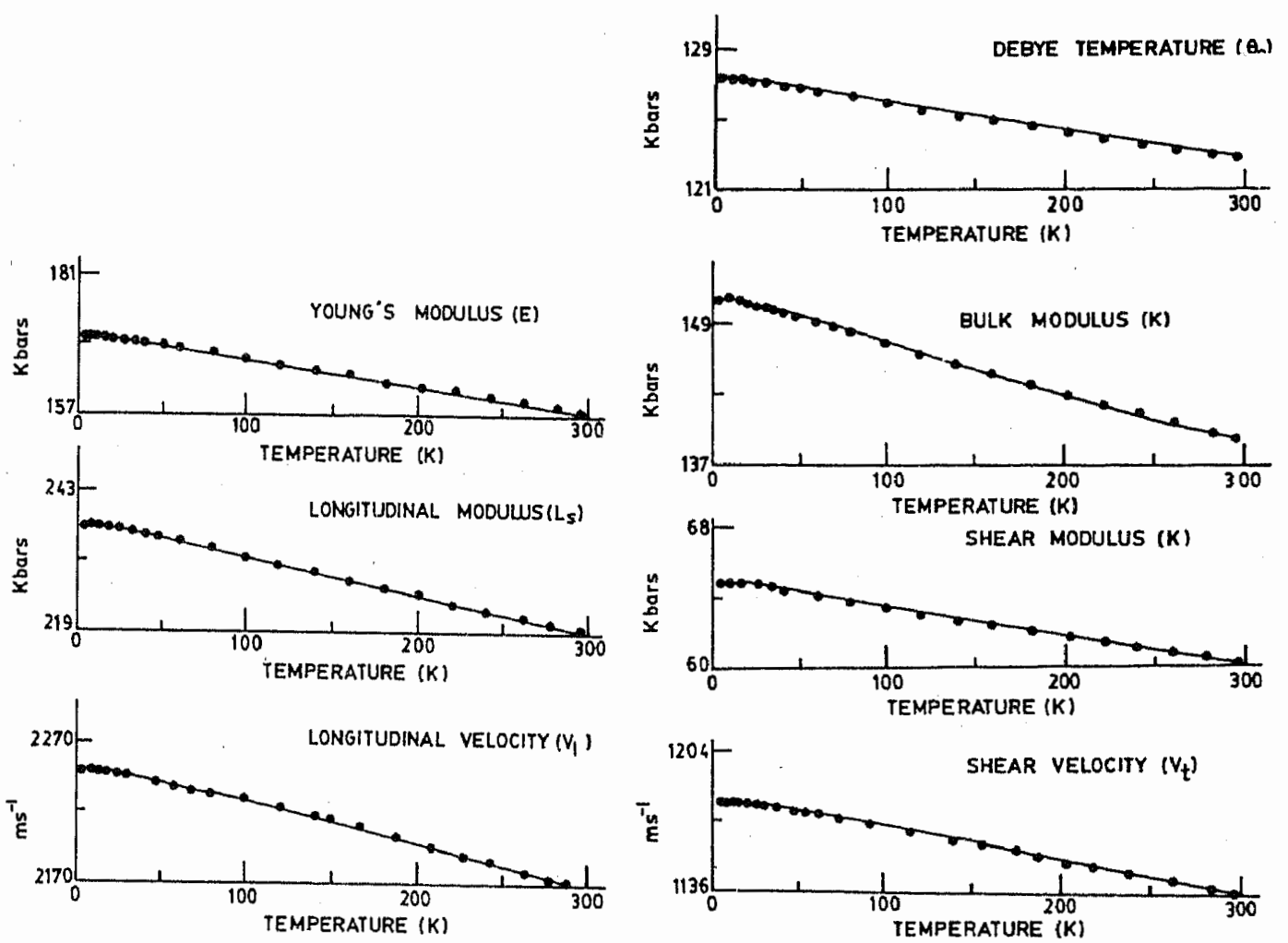

Figure 1. Temperature dependence of the elastic constants of $\mathrm{Ge}_{15} \mathrm{Sb}_{10} \mathrm{Se}_{75}$ glass.
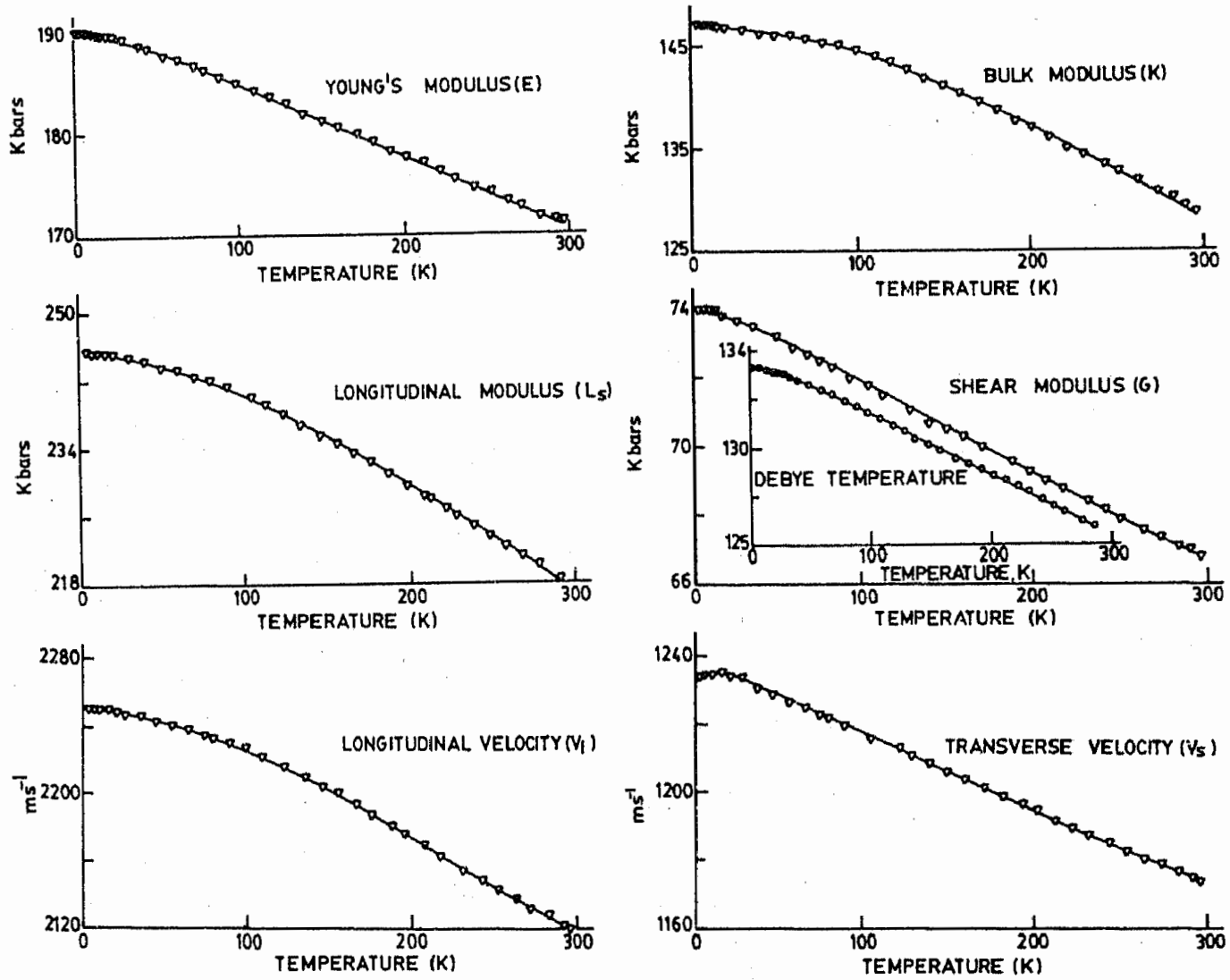

Figure 2. Temperature dependence of the elastic constants of $\mathrm{As}_{10} \mathrm{Sb}_{15} \mathrm{Se}_{75}$ glass. 
$\mathrm{Ge}_{20.84} \mathrm{Sb}_{15} \mathrm{Se}_{64.16}, \mathrm{Ge}_{16.67} \mathrm{Sb}_{20} \mathrm{Se}_{63.33}, \mathrm{Ge}_{12.5} \mathrm{Sb}_{25} \mathrm{Se}_{62.5}$ and $\mathrm{Ge}_{32} \mathrm{Sb}_{10} \mathrm{Se}_{58}$ ) and eight As-Sb-Se glasses $\left(\mathrm{As}_{20} \mathrm{Sb}_{15} \mathrm{Se}_{65}, \mathrm{As}_{25} \mathrm{Sb}_{15} \mathrm{Se}_{60}, \mathrm{As}_{30} \mathrm{Sb}_{15} \mathrm{Se}_{55}, \mathrm{As}_{30} \mathrm{Sb}_{10} \mathrm{Se}_{60}\right.$, $\mathrm{As}_{35} \mathrm{Sb}_{5} \mathrm{Se}_{60}, \mathrm{As}_{22} \mathrm{Sb}_{18} \mathrm{Se}_{60}, \mathrm{As}_{35} \mathrm{Sb}_{15} \mathrm{Se}_{60}$ and $\mathrm{As}_{10} \mathrm{Sb}_{15} \mathrm{Se}_{75}$ ) as a function of temperature from $300 \mathrm{~K}$ to $4.2 \mathrm{~K}$. Although a lot of data could be presented we give only representative data for each glass $\left(\mathrm{Ge}_{15} \mathrm{Sb}_{10} \mathrm{Se}_{75}\right.$ and $\mathrm{As}_{10} \mathrm{Sb}_{15} \mathrm{Se}_{75}$ ) (figures 1 and 2). All the elastic constants for all the glasses increase as the temperature is lowered. They reach a flat value around $4.2 \mathrm{~K}$.

The low temperature elastic moduli can be explained using the quasi-harmonic model of Claytor and Sladek (1978). To compute the elastic moduli using this model, one needs the variation of specific heat and thermal expansion at all temperatures which are not available for these glasses. Instead we follow the Lakkad's anharmonic oscillator model which is simple and does not need other parameters. Lakkad (1971) derived a simple expression to estimate the temperature dependence of the elastic constants using the anharmonic oscillator model. In this model if one knows the elastic moduli at two different temperatures along with the Debye temperature one can predict the elastic moduli at any other temperature.

Following Lakkad (1971) we get an expression for any elastic moduli $E$ at a temperature $T$ as

$$
E=E_{1}+\frac{\left(E_{1}-E_{2}\right)}{\left(T_{2}-T_{1}\right)}\left(T_{1}-T\right)
$$

in the high temperature limit, $\theta_{D} \ll T$.

$$
E=E_{1}+\frac{E_{1}-E_{2}}{T_{2}^{4}-T_{1}^{4}}\left(T_{1}^{4}-T^{4}\right)
$$

in the low temperature limit $\theta_{\eta} \gg T$, where $E_{1}$ and $E_{2}$ are the elastic constants at temperatures $T_{1}$ and $T_{2}$. Equation (1) has been used for temperatures greater than $20.5 \mathrm{~K}$ while equation (2) has been used in the range $20.5 \mathrm{~K}$ and $4.2 \mathrm{~K}$.

Figures 3 and 4 clearly show the fit of the experimental data points to the Lakkad's model, for both Ge-Sb-Se and As-Sb-Se glasses. Hence we can conclude that the low temperature elastic constants for the Ge-Sb-Se and As-Sb-Se glasses can be predicted by Lakkad's model.

\subsection{Composition dependence of the elastic constants of Ge-Sb-Se glasses}

The longitudinal velocity $\left(V_{L}\right)$, shear velocity $\left(V_{t}\right)$, longitudinal modulus $\left(L_{s}\right)$, Young's modulus $(E)$, bulk modulus $(K)$ and shear modulus $(G)$ for the $\mathrm{Ge}_{x} \mathrm{Sb}_{10} \mathrm{Se}_{90-x}$ glasses as the content of germanium is increased is shown in figure $5 \mathrm{a}$, at room temperature. The velocities and the elastic constants increase linearly up to 25 at. $\%$ of $\mathrm{Ge}$ and beyond this the changes are nonlinear, and the increase is steeper. Various properties like glass transition temperature $\left(T_{g}\right)$, electrical conductivity, activation energy $(\triangle E)$, and density (d) (Savage et al 1978; Giridhar et al 1980, 1981; Narasimham et al 1981; Sudha Mahadevan et al 1983, 1984) also exhibit extrema at $\mathrm{Ge}_{25} \mathrm{Sb}_{10} \mathrm{Se}_{65}$ composition. Since this nonlinear behaviour indicates a change in the basic structure of the glass Giridhar et al $(1980,1981)$ explained the properties on the basis of chemically oriented network model (CONM). 


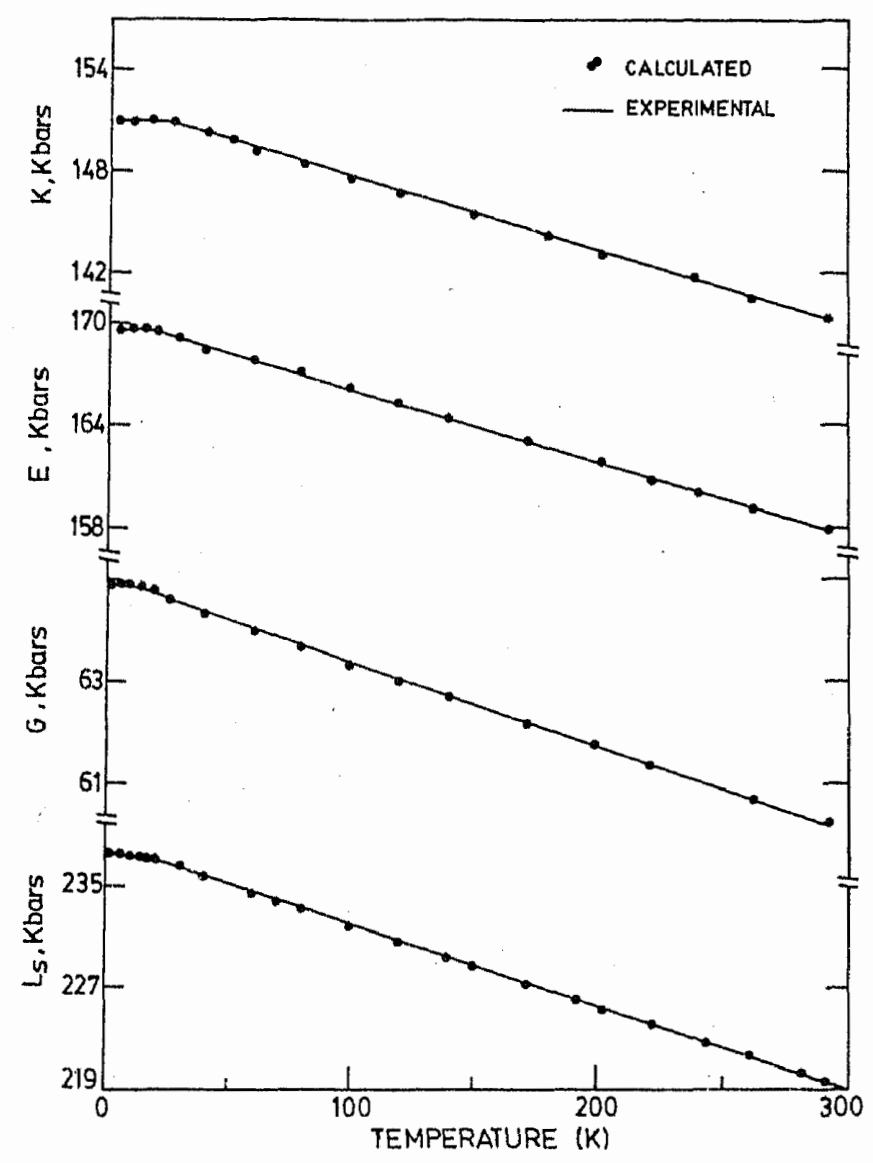

Figure 3. Temperature dependence of the calculated and experimental elastic constants of $\mathrm{Ge}_{15} \mathrm{Sb}_{10} \mathrm{Se}_{75}$ glass.

The composition $\mathrm{Ge}_{25} \mathrm{Sb}_{10} \mathrm{Se}_{65}$ can be written as $\left(\mathrm{GeSe}_{2}\right)_{25}\left(\mathrm{Sb}_{2} \mathrm{Se}_{3}\right)_{5}$. Thus the glass structure can be pictured to be made up of cross-linked three-dimensional structural units of $\mathrm{GeSe}_{2}$ and $\mathrm{Sb}_{2} \mathrm{Se}_{3}$ with $\mathrm{Se}$ or $\mathrm{Ge}$ in excess. At stoichiometric composition the bonds are heteropolar. If the $\mathrm{Ge}$ content is $<25$ at.\%, some of the original $\mathrm{GeSe}_{2} / \mathrm{Sb}_{2} \mathrm{Se}_{3}$ units are replaced by Se. Since Se is found in two-fold co-ordination, the strength of the resulting lattice would be lower than that of the stoichiometric composition.

In glasses with a small content of germanium, the three-dimensional tetrahedral $\mathrm{GeSe}_{4 / 2}$ and trigonal $\mathrm{SbSe}_{3 / 2}$ units are statistically distributed among the chains of extra selenium. When the germanium content in the giass increases, the excessive chains of selenium become gradually connected and the three-dimensional network of the glass develops due to increase of $\mathrm{GeSe}_{4 / 2}$ units. This results in the strengthening of the glass framework and an increase of ultrasound velocity and elastic moduli as well as in the decrease of adiabatic compressibility. The selenium chains gradually degenerate into bridges of two selenium atoms -Se-Se-, while the increase of germanium over 15-20 at. \% leads to their disappearance. The glass network in this part of compositions begins to build up from tetrahedrons $\mathrm{GeSe}_{4 / 2}$ and pyramids $\mathrm{SbSe}_{3 / 2}$ directly bonded to one another. This is completed in the glass containing 25 at. $\%$ of germanium, which lies on the pseudobinary section $\mathrm{GeSe}_{2}-\mathrm{Sb}_{2} \mathrm{Se}_{3}$ and in which there is no excess selenium. The disappearance of bonds type -Se-Se-, that contribute to more advantageous space- 


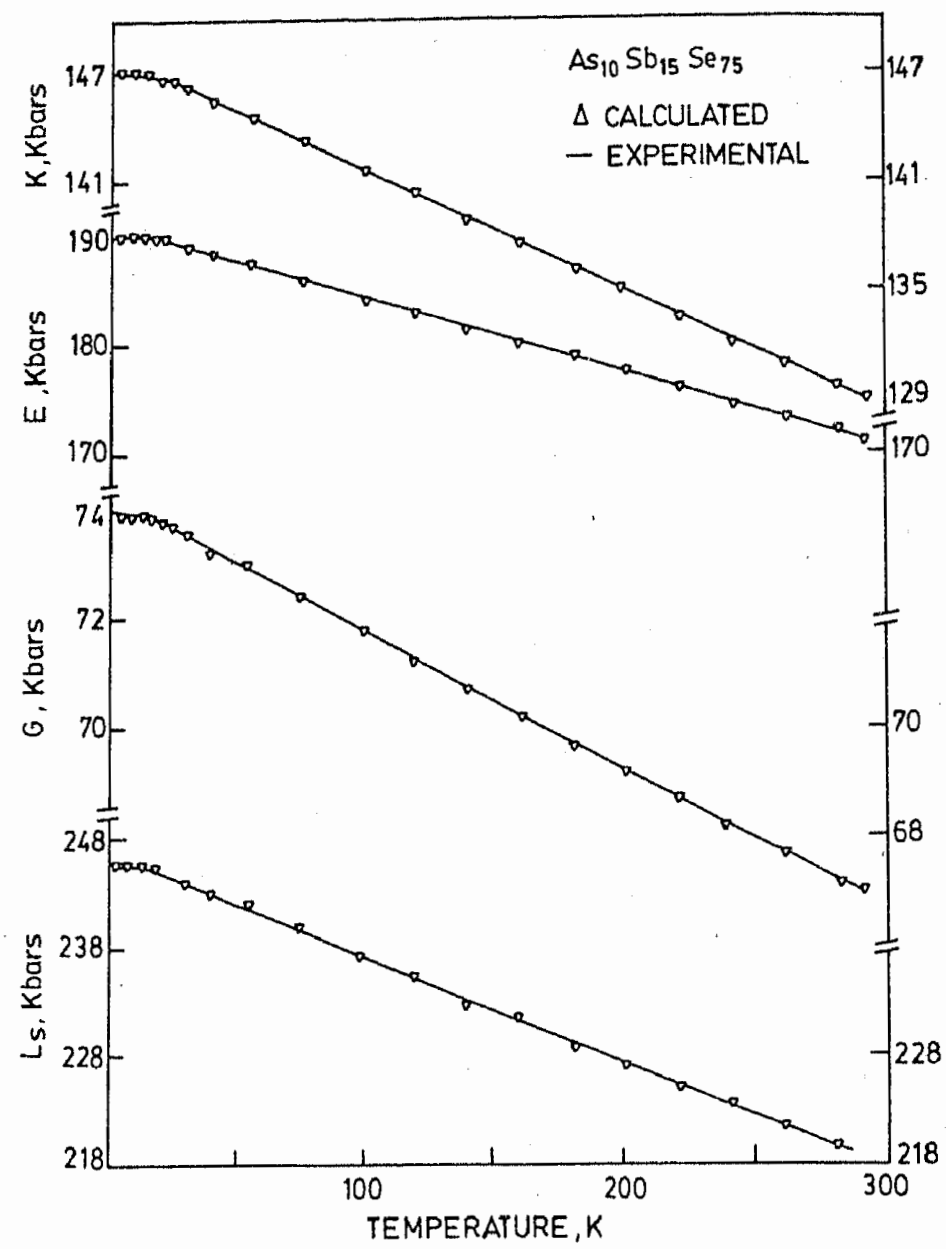

Figure 4. Temperature dependence of the calculated and experimental elastic constants of $\mathrm{As}_{10} \mathrm{Sb}_{15} \mathrm{Se}_{75}$ glass.

packing of three-dimensional $\mathrm{GeSe}_{4 / 2}$ and $\mathrm{SbSe}_{3 / 2}$ units, result in the loosening of the structure and a decrease of density. The increase of germanium content over the stoichiometric relationship both in the binary system $\mathrm{Ge}-\mathrm{Se}$ and in $\mathrm{Ge}$-Sb-Se leads to an increased density; hence the moduli of elasticity rise again. Further $\mathrm{Ge}_{x} \mathrm{Se}_{100-x}$ and $\mathrm{Ge}_{x} \mathrm{As}_{60-x} \mathrm{Se}_{40}$ glasses (Ota et al 1978; Tille et al 1977) exhibit a steep rise in velocities and elastic properties for Ge-rich glasses.

At room temperature the stoichiometric $\mathrm{Ge}-\mathrm{Sb}$-Se glasses with $\mathrm{Sb}=10,15,20$ and 25 have almost constant velocities and elastic constants as seen in figure $5 \mathrm{~b}$.

The bulk modulus $(K)$ is related to mean atomic volume $\left(V_{a}\right)$ by $K=$ constant $\times V_{a}^{-m}$, $m=4 / 3$ for a wide range of materials including alkaline earth silicate glasses. and $m=4$ for oxide and As-Se glasses. Glasses behave like crystals in showing an increase in bulk modulus with a decrease in volume. This trend is reversed in $\mathrm{GeS}_{2}-\mathrm{GeSe}_{2}$ (Ota et al 1978) and $\mathrm{As}_{2} \mathrm{~S}_{3}-\mathrm{As}_{2} \mathrm{Se}_{3}$ glasses (Ota et al 1973; Thompson and Bailey 1978). Variation of $\Delta E, \log \sigma, T_{g}$ with atomic percent of $\mathrm{Ge}$ for Ge-Se-Sb glasses and $\log K$ vs $\log V_{a}$ for $\mathrm{Ge}_{x} \mathrm{Sb}_{10} \mathrm{Se}_{90-x}, \mathrm{Ge}_{x} \mathrm{As}_{20} \mathrm{Se}_{80-x}$ and $\mathrm{Ge}_{x} \mathrm{Se}_{100-x}$ containing $\mathrm{Ge}$ and $\mathrm{Se}$ as common elements are shown in figure 6. Taking the stoichiometric composition as reference in the $\mathrm{Ge}_{x} \mathrm{Sb}_{10} \mathrm{Se}_{90-x}$ system an increase in Se content reduces both mean atomic volume and bulk modulus. This may be due to weakening of structure due to an increase in chains. However the relation $K=$ const $\times V_{a}^{-m}$ predicts that a decrease in 

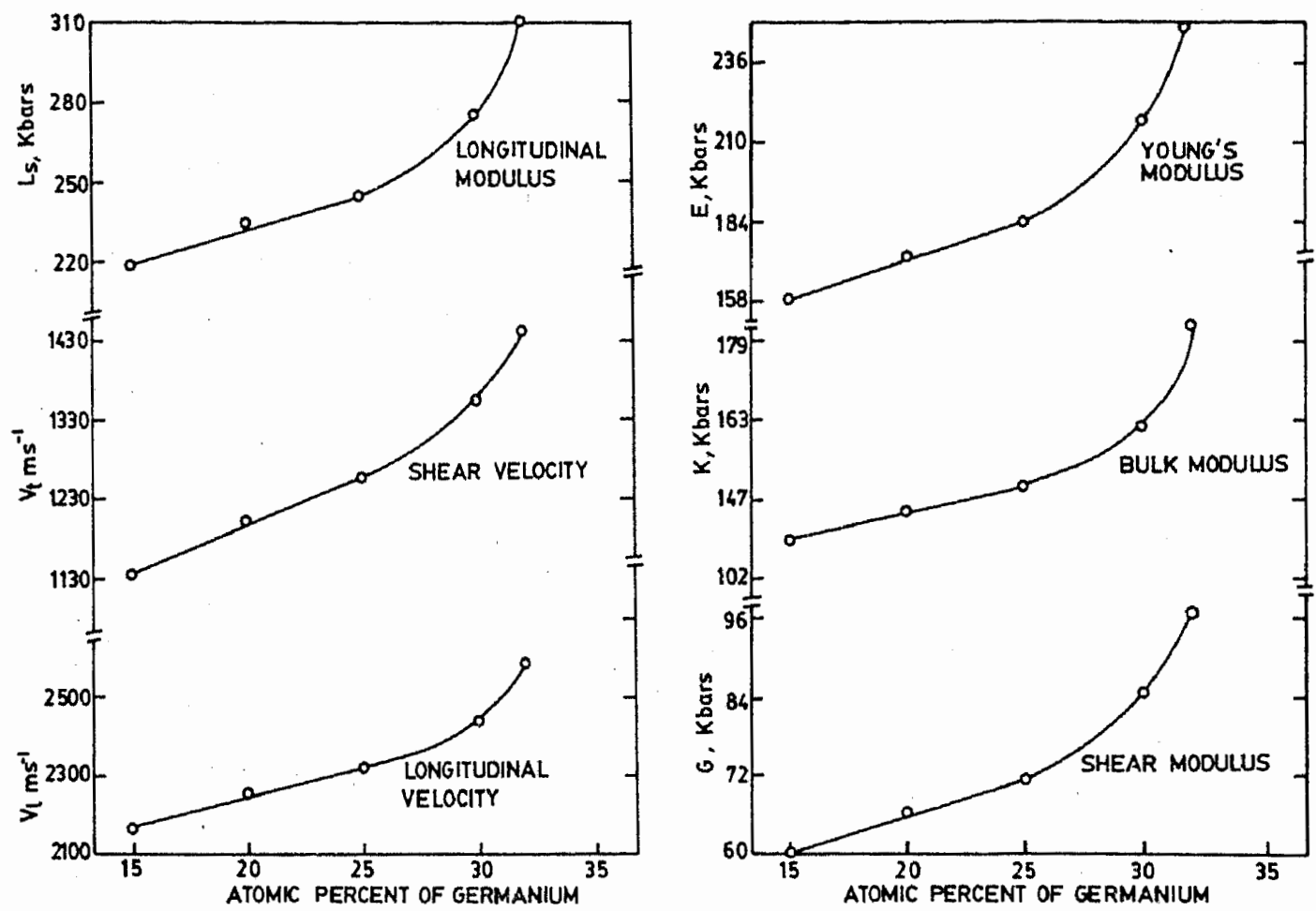

Figure 5. Variation of velocities and elastic moduli of $\mathrm{Ge}_{x} \mathrm{Sb}_{10} \mathrm{Se}_{90-x}$ glasses as Ge content is varied.
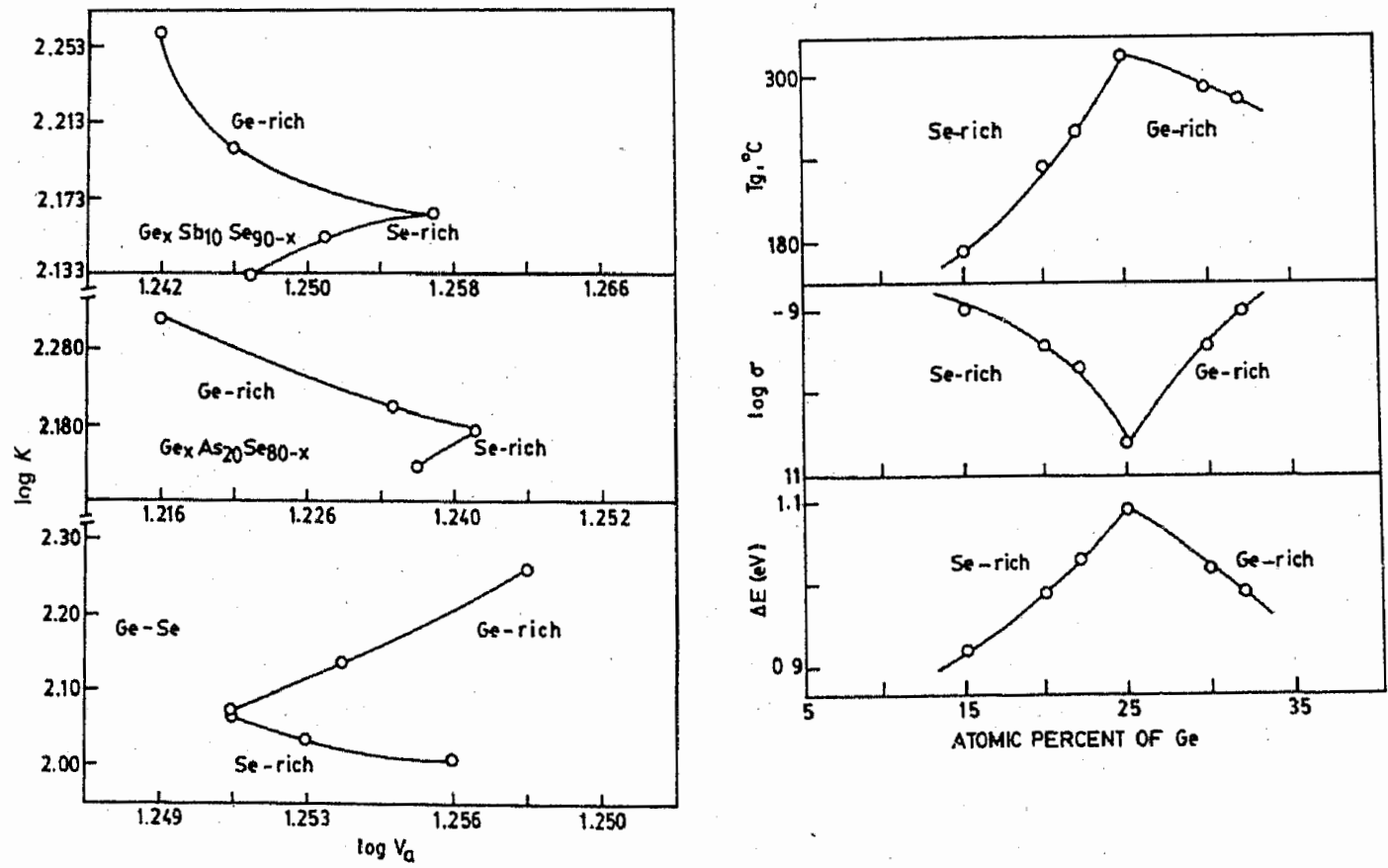

Figure 6. (a) The variation of $\log K$ with $\log V_{a}$ for $\mathrm{Ge}_{x} \mathrm{Sb}_{10} \mathrm{Se}_{90-x}, \mathrm{Ge}_{x} \mathrm{As}_{20} \mathrm{Se}_{80-x}$ and $\mathrm{Ge}_{x} \mathrm{Se}_{100-x}$ glasses. (b) The variation of $\Delta E, \log \sigma$ and $T_{g}$ with $\mathrm{Ge}$ content for Ge-Sb-Se glasses. 


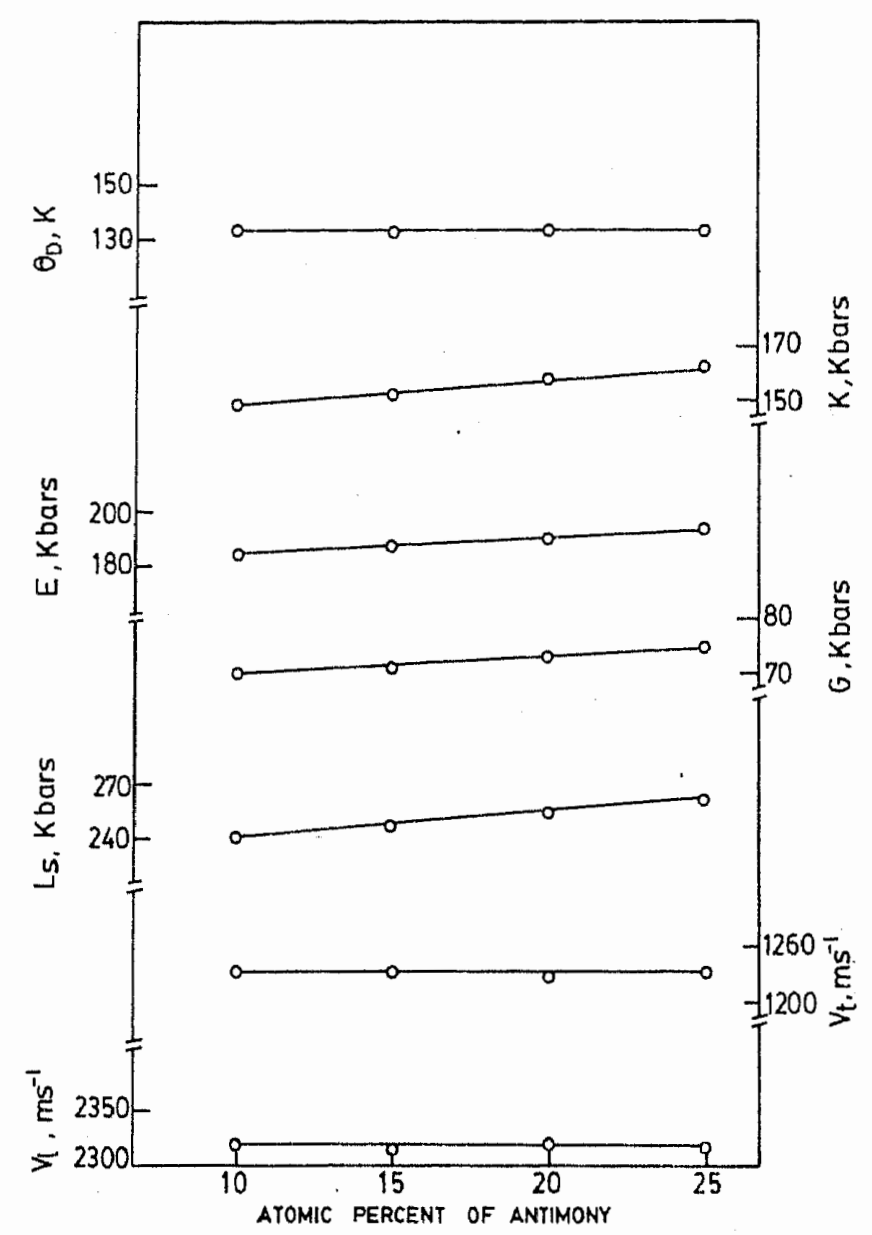

Figure 7. Variation of elastic properties for the stoichiometric $\left(\mathrm{GeSe}_{2}\right)_{1-c}\left(\mathrm{Sb}_{2} \mathrm{Se}_{3}\right)_{c}$ glasses of Ge-Sb-Se system.

volume should lead to an increase of bulk modulus $(K)$. Thus the type of bonding seem to play a prominent role in deciding the bulk modulus in addition to volume. For the Ge-rich glasses the bulk modulus increases while the volume decreased; this is due to an increase of tetrahedral network due to excess $\mathrm{Ge}$. The $\mathrm{Ge}_{x} \mathrm{As}_{20} \mathrm{Se}_{80-x}$ glass also shows a behaviour of bulk modulus with mean atomic volume similar to the $\mathrm{Ge}_{x} \mathrm{Sb}_{10} \mathrm{Se}_{90-x}$ glass (figure 7). $\mathrm{Ge}_{x} \mathrm{Se}_{100-x}$ glasses indicate a complete reversal in the general trend. Here taking $\mathrm{Ge}_{20} \mathrm{Se}_{80}$ as reference because the glass structure is made up of $\mathrm{GeSe}_{4}$ tetrahedrae for Ge-rich glasses, the mean atomic volume as well as the bulk modulus increase. A similar behaviour is observed for $\mathrm{Ge}-\mathrm{Sb}-\mathrm{S}$ (Hayes et al 1974). Hence the type of bonding in the glasses is likely to determine the bulk modulus than increase in volume. For Se-rich region while the volume increases, the bulk modulus decreases. Thus an increase in Se content and volume contributes to a decrease of bulk modulus. The stoichiometric Ge-Sb-Se glasses have almost the same mean atomic volume and bonding leading to a constant bulk modulus. The Poisson's ratio $(\sigma)$ of Se-rich $\mathrm{Ge}-\mathrm{Sb}$ Se glasses is higher than the $\sigma$ of Ge-rich glass. This may be due to the structure of glass undergoing a change from chain-like to network form.

The Debye temperature $\left(\theta_{D}\right)$ is almost constant $(133 \mathrm{~K})$, because the mean atomic volume and velocities are constant.

The composition dependence of the low temperature velocities and elastic constants reveals that for $\mathrm{Ge}_{x} \mathrm{Sb}_{10} \mathrm{Se}_{90-x}$ group of glasses, various properties increase smoothly 
up to stoichiometric composition $\mathrm{Ge}_{25} \mathrm{Sb}_{10} \mathrm{Se}_{65}$, whereas beyond this there is a steeper rise. In the stoichiometric glasses with $\mathrm{Sb}=10,15,20$ and 25 the parameters are almost constant. It is clear that the composition dependence at low temperatures follows the same pattern as that at room temperature except for an increase in magnitude. Hence the composition dependence can be explained using the CONM model.

In order to examine the role of antimony in the low temperature elastic properties of $\mathrm{Ge}-\mathrm{Sb}-\mathrm{Se}$ glasses, the percentage change of elastic properties between room temperature and $77 \mathrm{~K}$ is studied. In the stoichiometric glasses with $\mathrm{Sb}=10,15,20,25$ at. \%, the percentage change in $V_{L}, V_{t}, L_{s}, G, E, K$ and $\theta_{D}$ are respectively $-2 \cdot 36,-2 \cdot 49,-4.78$, $-5.99,-4.05$ and -2.90 and the change is the same for all compositions. This indicates that for stoichiometric glasses of Ge-Sb-Se system, though the $\mathrm{Sb}$ content changes, the percentage change in elastic constants is the same. Thus antimony seems to influence very little the elastic behaviour for $\mathrm{Ge}-\mathrm{Sb}$-Se glasses.

For $\mathrm{Ge}_{x} \mathrm{Sb}_{10} \mathrm{Se}_{90-x}$ glasses with antimony kept at 10 at. $\%$, while the content is increased (Se decreased), the elastic constants initially decrease, reach a minimum at $\mathrm{Ge}=30$ at. \% and then increase again. So, we find that only Se or Ge content seems to induce changes in the elastic properties at low temperatures. Hence we conclude that $\mathrm{Se}$ or $\mathrm{Ge}$ content decides the low temperature elastic behaviour of $\mathrm{Ge}-\mathrm{Sb}$-Se glasses.

\subsection{Composition dependence of the elastic constants of As-Sb-Se glasses}

The As-Sb-Se glasses can be grouped into two categories. (a) Glasses whose composition can be represented as ( $\mathrm{AsSb})_{40} \mathrm{Se}_{60}$. These fall along the $\left(\mathrm{As}_{2} \mathrm{Se}_{3}\right)\left(\mathrm{Sb}_{2} \mathrm{Se}_{3}\right)$ pseudo-binary section representing the stoichiometric composition of the As-Sb-Se system. (b) Glasses whose composition can be represented as $\mathrm{As}_{x} \mathrm{Sb}_{15} \mathrm{Se}_{85-x}$. In these glasses, the $\mathrm{As}_{25} \mathrm{Sb}_{15} \mathrm{Se}_{60}$ is taken as a reference stoichiometric composition and the
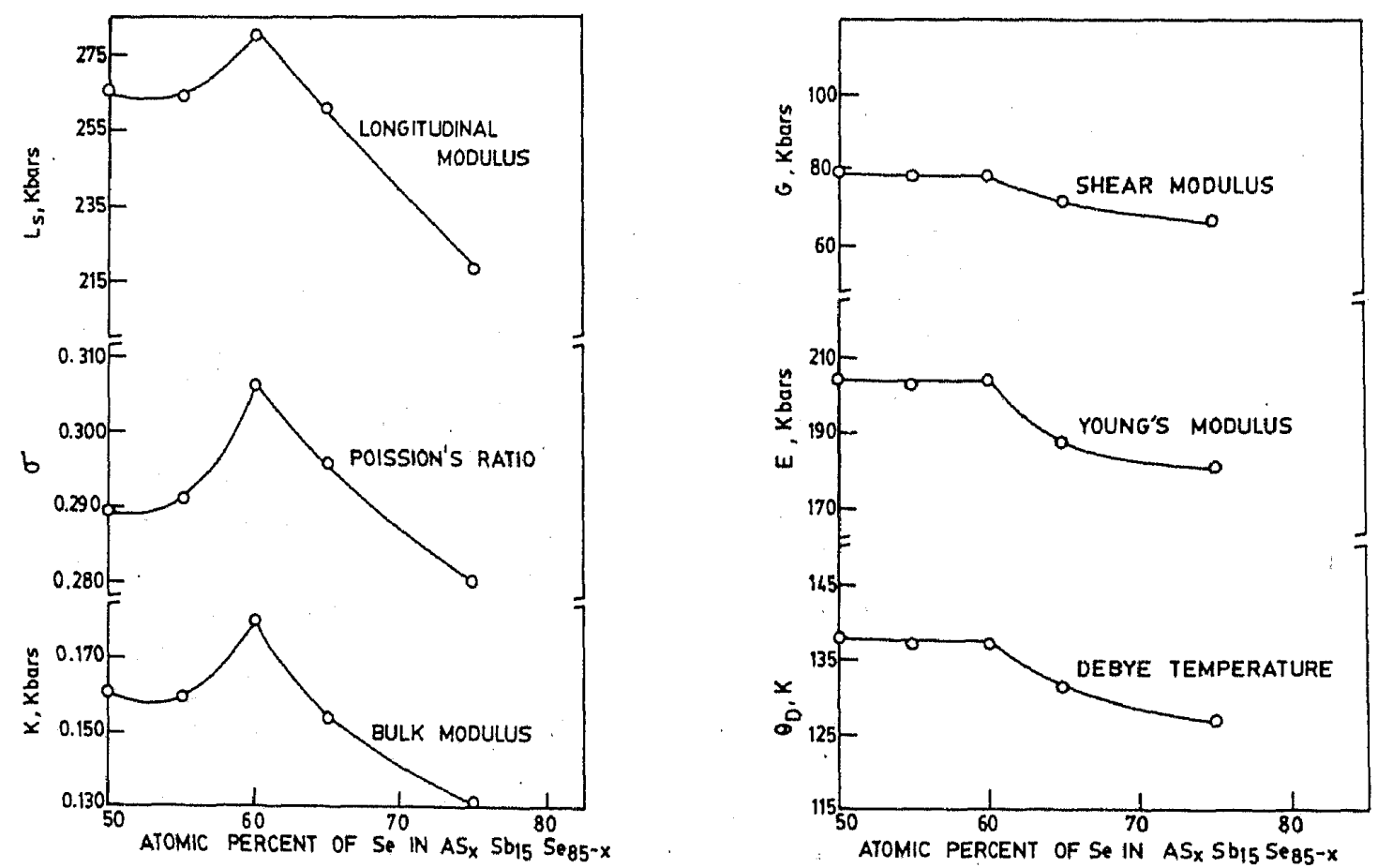

Figure 8. Variation of elastic moduli as a function of $\mathrm{Se}$ content for $\mathrm{As}_{x} \mathrm{Sb}_{15} \mathrm{Se}_{85-x}$ glasses. 
glasses with $>60$ at. $\%$ of Se are called Se-rich glasses and glasses with $<60$ at. $\%$ of Se are called As-rich glasses.

The variation of longitudinal modulus $\left(L_{s}\right)$, Poisson's ratio $(\sigma)$, Debye temperature $\left(\theta_{D}\right)$, shear modulus $(G)$, Young's modulus $(E)$ and bulk modulus $(K)$ for the $(\mathrm{As}, \mathrm{Sb})_{40} \mathrm{Se}_{60}$ glasses as the Sb content is increased is shown in figure 9. It is clear that the elastic moduli increase monotonically smoothly. The room temperature elastic constants are in good agreement with the measurements of Giridhar et al (1984). The extrapolated elastic moduli for zero at.\% of $\mathrm{Sb}$ give the elastic constants for $\mathrm{As}_{2} \mathrm{Se}_{3}$ which are in good agreement with the measurement of Soga and Kungi (1973) for $\mathrm{As}_{2} \mathrm{Se}_{3}$.

The observation of the increase of mean atomic volume in isostructural compounds indicates an increase of bulk modulus (Anderson and Nafe 1965). For these glasses it is seen that the bulk modulus increases with increasing $\mathrm{Sb}_{2} \mathrm{Se}_{3}$ content while the corresponding volume is also increased. This shows that the type of bonding rather than the volume has a greater influence in determining the bulk modulus of these glasses. Such a dependence has been observed in many other glasses (Sudha Mahadevan et al 1983).

The variation of $T_{g}$, density have been observed by Giridhar et al and the elastic moduli do depend on these parameters. A qualitative explanation can be given for the variation of elastic moduli as follows. The $T_{g}$ shows a slight increase with the increasing $\mathrm{Sb}$ content, indicating the strengthening of glass which is reflected in the increase of elastic moduli. The small increase is because $\mathrm{As}$ and $\mathrm{Sb}$ are isovalent and replacement of As by Sb does not drastically alter the basic structure of the glass. This is supported by the nearly equal bond energies of $52 \mathrm{kcal} / \mathrm{mol}$ and $51 \mathrm{kcal} / \mathrm{mol}$ of As-Se and Sb-Se bond (Giridhar et al 1982).

The elastic moduli $G, E, K, L_{s}, \sigma$ and Debye temperature $\theta_{D}$ for $\mathrm{As}_{x} \mathrm{Sb}_{15} \mathrm{Se}_{85-x}$ glasses as the Se content is increased is shown in figure 8. Taking $A s_{25} \mathrm{Sb}_{15} \mathrm{Se}_{60}$ as the
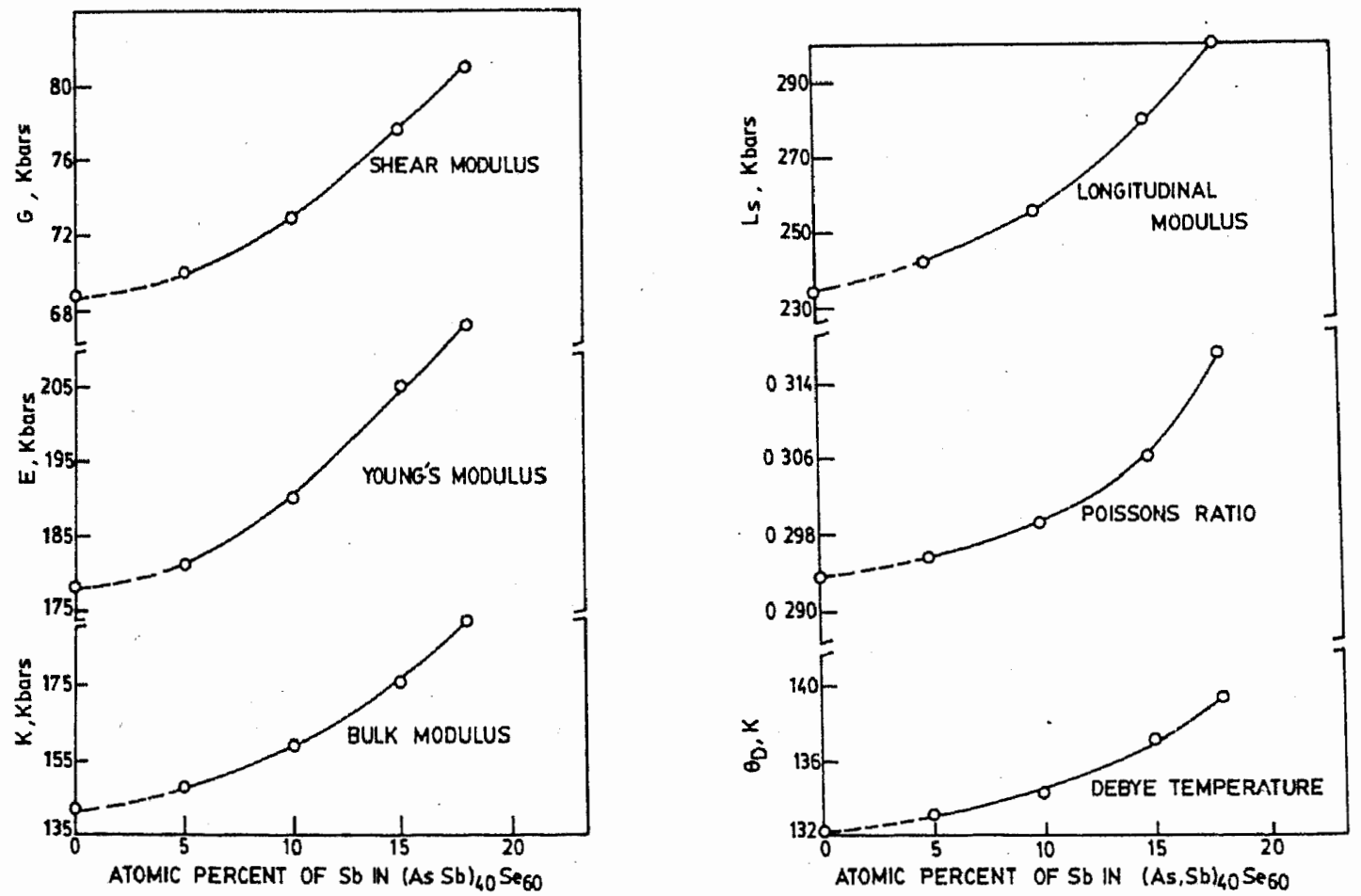

Figure 9. Variation of elastic moduli for $(\mathrm{As}, \mathrm{Sb})_{40} \mathrm{Se}_{60}$ glasses as a function of $\mathrm{Sb}$ content. 
based glasses are much tougher than As-based glasses, which is clearly indicated by th higher elastic moduli in Ge-based glasses. It also shows that the Ge-based glasses ar less sensitive to temperature than As-based glasses.

\section{Conclusions}

(i) The elastic moduli of both Ge-Sb-Se and As-Sb-Se glasses smoothly increases as th temperature is decreased down to $4 \cdot 2 \mathrm{~K}$. (ii) The temperature dependence of lor temperature elastic constants can be explained with Lakkad's anharmonic oscillato model for both the glasses. (iii) The composition dependence of elastic moduli both a low and room temperatures can be explained using the chemically ordered networ. model. (iv) The germanium-based glasses are much harder and less sensitive to th temperature than arsenic based glasses.

\section{Acknowledgements}

We specially thank Dr A K Singh and Dr (Mrs) Sudha Mahadevan for the samples use in the study.

\section{References}

Anderson O L and Nafe J E 1965 J. Geophys. 703951

Baidakov L A 1966 Solid state chemistry (ed.) R L Myuller (New York: Consultants Bureau) p. 94 Claytor T N and Sladek R J 1978 Phys. Rev. B18 5842

Giridhar A, Narasimham P S L and Sudha Mahadevan $1980 \mathrm{~J}$. Non-Cryst. Solids 37165

Giridhar A, Narasimham P S L and Sudha Mahadevan 1981 J. Non-Cryst. Solids 4329

Giridhar A and Sudha Mahadevan 1982 J. Non-Cryst. Solids 511001

Giridhar A, Sudha Mahadevan and Singh A K 1984 Bull. Mater. Sci. 61001

Hayes D J, Rechtin M D and Hilton A R 1974 Proc. Symp. on ultrasonics (ed.) J. de Klerk (New York Academic Press)

Kartha P E S, Padaki V C and Gopal E S R 1980 Proc. Int. Cong. Exhibition on Ultrasonics (ICEV-80) Ner Delhi, p. 19

Lakkad S C 1971 J. Appl. Phys. 42 11, 4277

McSkimin H J 1961 J. Acoust. Soc. Am. 3312

Myuller R L (ed.) 1966 Solid state chemistry (New York: Consultants Bureau) p. 1

Narasimham P S L, Giridhar A and Sudha Mahadevan 1981 J. Non-Cryst. Solids 43 301, 365

Ota R, Soga N and Kunugi M 1973 J. Soc. Mater. Sci. Jpn 22567

Ota R, Yamata T, Soga N and Kunugi M 1978 J. Non-Cryst. Solids 2967

Padaki V C, Lakshmikumar S T, Subramanyam S V and Gropal E S R 1985 Pramana-J. Phys. 1725

Papadakis E P 1976 Physical acoustics (eds) W P Mason and R N Thurston (New York: Academic Pres: Vol. 12

Savage J A and Nielsen S 1964 Phys. Chem. Glasses 582

Savage J A, Webber P J and Pitt A U 1978 J. Mater. Sci. 13859

Soga $N$ and Kunugi M 1973 J. Phys. Chem. Solids 342143

Srinivasan K R, Sivaraman A, Nagarajan N, Ramakrishnan and Gopal E S R 1975 Proc. Symp. Transduce Technology Cochin, India (Cochin: NPOL Press) p. 283

Sudha Mahadevan, Giridhar A, Narasimham P S L and Singh A K: J. Non-Cryst. Solids 65233

Sudha Mahadevan, Giridhar A and Singh A K 1983 J. Non-Cryst. Solids 57423

Thompson J C and Bailey K E 1978 J. Non-Cryst. Solids 27161

Tille U, Frischat G H and Leers K J 1977 Fourth Int. Conf. on Non-Cryst. Solids, Zellerfeld (ed.) G H Frische (New York: Trans-Tech Publication)

Webber P J and Savage J A 1976 J. Non-Cryst. Solids 20271 